\title{
REFLEXÕES SOBRE A CIÊNCIA \\ DO DIREITO
}

Nely Lopes Casali 1

SUMARIO: SUMARIO: 1. A Ciència do Direito, Modelo Analitico e Empirico-2. A Ciência do Direito e o Fenomeno da Positivação - 3. A Teria da Nonma e o Modelo Pragmatico 4. Os Elementos da Noma Jundica - 5. O Sistema Normativo - 5.1. O Problema da Validade - 5.2. O Problema da Efetividade - 6. O Discurso Normativo - 7. O Problema da Sança - 8 Situaçós Jumidicas Subjetivas - 8.1. O Poder Juridico - 8.2 Direito Subjetivo.

RESUMO: Coletânea de reflexöes sobre alguns dos principais temas da Ciencia do Diteito, que väo desde a discussão quanto ao seu método, o fenomeno da positivacão, a analise das nomas juridicas, o sistema e o discurso normativo, algumas consideracoes sobre a sançä, ate a analise, ao final, das chamadas situdeses juridicos subjetivas.

PALAVRAS-CHAVE: Ciência do Direito, Rellexôes, Noma Juridica, Sistema Nomativo, Discurso Nomativo, Sança, Direito Subjetivo.

ABSTRACT: Reflections about some of the most important subjects of the law science, that go from the discussion of its methods, the positive law phenomena, the analysis of the laws, the normative system and speech, some considerations about the sanctions, to the andysis, in the end, of the so called subjective juridical situations.

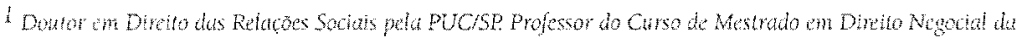
Eniveridade Estadtul de Londinte
} 


\section{A CIÊNCIA DO DIREITO, MODELO ANALÍTICO E EMPIRICO}

A Ciência do Direito tem por objeto estabelecer um "sistema de conhecimentos sobre a realidade juridica"2.

Como toda ciência, precisa estabelecer os caminhos que devam ser seguidos, para se chegar ao conhecimento de seu objeto.

A Ciência do Direito, eminentemente social, não pode se servir dos mesmos métodos da ciência da natureza, onde os fenômenos são repetitivos, determinados por causas pré-estabelecidas e com efeitos antecedentemente estimados.

A Ciência do Direito, por ter objeto próprio, há de ter, também, método próprio. Entretanto, não há unanimidade quanto à natureza de seu método, existindo três correntes que tentam explicá-lo: a histórica, a analitica e a empirica:

a) a primeira corrente insiste na historicidade do método e considera a Ciência do Direito uma atividade metódica que procura conhecer o sentido do fenomeno juridico, através de suas variaçoes no espaço e no tempo;

b) a segunda corrente defende o método analítico, atraves do qual ocorre um processo de decomposiça do todo em seus segmentos, separados por classificaçoes e sistematizaçoes, que methor conhecimento possibilitam de cada um e do todos;

c) finalmente, a terceira corrente, desprezando a historicidade do método, pretende estabelecer um relacionamento do Direto com a condicoes empiricas subjacentes, para explicar as "estruturas funcionais".

No confronto com estes modelos, nâo resta a menor dúvida que o método analitico se destaca por ser o construtor da ciência universal; o espírito analítico joga com questões dicotômicas, para buscar a verdade; vg, " houve furto ou houve roubo?"; "há posse ou há propriedade?". O cientista

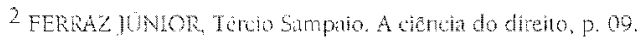

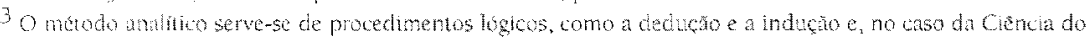

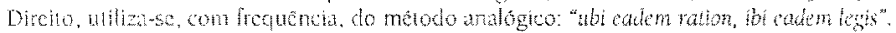


do Direito, através do método analítico, pode se utilizar da indução e da dedução, isto é, dos procedimentos conclusivos de proposições do particular para o geral e vice versa, ou seja, do geral para o particular.

método analítico jurídico está se endereçando, atualmente, para o pensamento tecnológico, o que representa um extraordinário passo para o aperfeicoamento da Ciência do Direito.

\section{A CIENCIA DO DIREITO E O FENOMENO DA POSITIVAÇAO}

Ciencia do Direito, costuma-se dizer, é um sistema de conhecimento sobre a realidade do mundo jurídico, cujo centro é ocupado pelo homem.

o homem, numa situaçăo ambigua, pela sua açăo cria, modifica, transforma, amplia, reduz as estruturas da sociedade - cria o Direito, do qual e destinatário.

Positivação é o fenomeno através do qual o homem, por sua decisão, modifica, transforma o Direito, adaptando-o às exigencias, anseios, idélas e ideais.

Esta "legalização do cambio do direito" faz com que o direito seja mutável, dinämico, envolvente e evolutivo, num acompanhar incessante de todas as mutaçoes sociais.

Positivação e decisão são dois fenômenos que caminham passo a passo, inseparavelmente, e expressam a liberdade do homem em escolher o seu sistema juridico.

O Direito Positivado é aquele provindo da decisão do homem, completamente apartado do Direito Natural.

Daí dizer NIKLAS LUHMANN que devemos entender por positivação do direito o fenômeno segundo o qual "todas as valorações, normas e

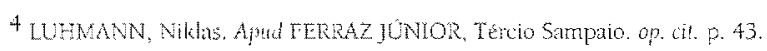


expectativas de comportamento na sociedade têm que ser filtradas através de processos decisórios antes de poder adquirir a validade"s.

A positivação do Direito seria, em termos politicos, a participação de todos, sem distinção, nas decisóes em torno da realidade jurídica.

\section{A TEORIA DA NORMA E O MODELO PRAGMÁTICO}

As palavras que se usam para expressar pensamentos são signos.

Falar é uma ação indicativa em que se atribui palavras aos objetos. $O$ ato de falar é algo corrente, contínuo, formando o discurso.

Considera-se, assim, discurso ou ato de falar a ação dirigida a alguém (ouvinte) por alguém (orador) com apelo ao entendimento de quem ouve. $\mathrm{O}$ entendimento e o aprender correspondem à possibilidade de o ouvinte repetir o discurso.

As regras para o estudo do discurso são três: sintaxe, semântica e pragmática. Na sintaxe, procura-se estabelecer a relação de um signo com outro signo; na semântica, a relação do signo com seu objeto; e, na pragmática, a relação signo com o usuário.

Se se transportar estas regras para a teoria da norma jurídica, pode-se estabelecer os modelos sintáticos, semänticos e pragmáticos.O que é pragmática? É o estudo dos signos tendo em vista seus usuários. O que é o modelo pragmatico? E o estudo da norma juridica, tendo em vista seus usuários.

A estrutura do modelo pragmático pousa em 5 pontos básicos:

d) o principio básico da análise da pragmática é a interação - troca de mensagens; comunicaçar, perguntar e responder; perguntar significa estar inseguro quanto ao seu proprio comportamento;

b) comunicaçâo verbal (digitab) e comunicação analógica; na comunicação verbal, emaname, com as caracteristicas de semanticamente pobre e sintaticamente rica; na

5 Apud FERRAz JüNOR, Tércio Smpaio. op. cit. p. 
comunicacáo andogica, a caracteristica inversa da anterior: semanticamente rica (por exemplo: chorar, rir, semblante alegra, sério, etc) e sintaticamente pobre;

c) nivet do relato - expressáno do modo verbal; nivel do cometimento - transmidido andogicamente; o relato a a informacäo transmitida e o cometmento é uma informaço sobre a informaça, que diz e orienta como a informaça transmitida deve ser entendida (exemplo: relato - "você esta muito gordo", cometimento - "digo-lhe isto porque gostaria de vê lo mais elegante, participando do nosso esporte preferido");

d) relacoes simetricas - aquelas em que as partes são paritarias; relacoes complementares - aquelas em que as portes estäo hiefarquicamente postas umas em retaço ds outras;

c) Ultima caracteristica do discurso e a estrategia (exemplo: a mulher pretende se equiparar do homem $b$ para isto, usa de certos recursos e planos anteriomente estudados e projetados).

Esta é a sintese do modelo pragmálico.

\section{OS ELEMENTOS DA NORMA}

A norma junidica é entendida como um discurso; sob o ângulo pragmatico, é interacão em que alguém dá a entender a outrem alguma coisa.

O conteudo da notma é um pensamento, uma proposicão juridica de natureza prática; vale dizer, a norma é uma orientaçäo para a açao humana; e uma regra segundo a qual devem ser orientadas as acoes.

Como em todas as nomas, as nomas junidicas têm seus caracteres próprios, distintivos dos das demais. Em primeiro lugar, em comum com as regras gramaticais, as nomas jurídicas têm o caratel de orientaça, sendo um imperativo posituo emanado de uma vontade mais forte, por forca de un sistema juridico ou da força propriamente dita.

Sendo relação entre vontades, as normas juridicas são interpessoais e somente existem no mundo social, nảo existindo no mundo da natureza, onde prevalecem as relaçoes de causa e efeito.A noma juridica, como discurso linguistico, tem umbilical vinculacão com o principio da interacão, 
que é a relaçăo entre o orador e o ouvinte, estabelecendo uma situação comunicativa e um sistema comunicativo.

Esta situação comunicativa tem como elementos o repertório e a estrutura. O repertório, por sua vez, é constituido pelos seguintes elementos: orador, ouvinte e questão.

A estrutura pode ser dialógica ou monológica.

Na relaçäo orador $\mathrm{x}$ ouvinte $\mathrm{x}$ questão, distingue-se o relato, o cometimento e a estratégia. Relato é a informação contida na mensagem transmitida pelo orador ou pelo comunicador normativo e cometimento é a informaça sobre o modo de encarar a mensagem. Em outras palavas, o relato é a informação transmitida; o cometimento é uma informação sobre a informaça, que diz como a informação transmitida deve ser entendida.

O objeto do discurso normativo da norma jurídica é a decisão que nele se encerra, Isto implica que as normas possam ser questionadas de dois modos distintos: "questio certa" e "questio dubia".

\section{O SISTEMA NORMATIVO}

Sistema é um conjunto de objetos e seus atributos e suas respectivas inter-relaçoes, de conformidade com certas regras. Ao conjunto de objetose seus atributos dá-se o nome de repertório do sistema; às inter-relaçoes, de conformidade com as regras, dá-se o nome de estrutura do sistema.

Sabe-se que normas são interações em que alguém comunica a outrem alguma coisa, estabelecendo-se, por consequencia, uma relaçăo entre o comunicador e o ouvinte.

No discurso nomativo, há o relato e o cometimento è adequaçäo, de um ao outro, dá-se o nome de efetividade; há o problema da imunização do aspecto-cometimento de uma norma pelo aspecto-relato de outra norma, à qua se dá o nome de validade.

Os discursos são unidades compostas por orador, ouvinte, questões e estes são interligados por certas regras do dever de prova. 
O sistema normativo tem por objeto o conjunto destas unidades, discursos normativos ou, simplesmente, nomas.

Portanto, o objeto dos sistemas normativos (repertório do sistema) são as normas especificadas por seus dois importantes atributos: validade $e$ efetividade, sendo que as relaçoes entre as normas dão a coesão do sistema como um todo.

O sistema normativo juridico é um sistema do tipo "aberto", isto é, capaz de absorver elementos que vêm de fora e que são incorporados dentro de um certo limite; para HANS KELSENo, porém, o sistema normativo jurídico é fechado, por quanto todo ele se reduz à norma fundamental, sem possibilidade de qualquer aceitação de outros elementos estranhos à sua teoria pura do direito.

Para TERCIO SAMPAIO FERRAZ JUNIOR', o sistema nomativo juridico é aberto, porque ele não tem unifinalidade e, sim, equi-finalidade; isto é, podem ser alcançados os seus fins (os seus "jus") por diversos modos.

O sistema juridico normativo é "aberto" porque está em constante interligação com o mundo circundante, no qual existem os conflitos; estes conflitos entram dentro do sistema nomativo; parte é absorvida e parte é expelida; a linguagem cibernética chama a absorção de "imput" e a rejeição de "output".

Acontece com o sistema normativo juridico exatamente o que acontece com o corpo humano, que também é um sistema aberto, envolto por um modo circundante; o corpo humano também lem canais de "imput" (de entrada) e de "output" (de saida).

A imperatividade é uma qualidade do sistema. Validade e efetividade são atributos das normas que integram o sistema.

\subsection{O Problema da Validade}

A expressão "validade" tem várias significações. "Valiclade" é uma palavra que designa uma qualidade lingüística; designa material de natureza

\footnotetext{
6 Teoriapurado dieto p. 310.

7 Toria da noma juridica p. 141.
} 
lingǘstica. Validade designa uma relação. O termo validade pode ser trabalhado em termo de validade juridica.

O termo validade é termo chave no aparecimento do Direito, no século XIX.

Pelo esquema semiótico, os signos são relaçóes tríplices; se se substituir os signos pela norma, vê-se que ela também mantém uma relação triplice, com o meio, com o objeto e com o intérprete ou com o usuário.

Com o meio, mantém uma relação sintática; com o objeto, uma relação, ou melhor dizendo, uma interpretação semântica da validade e com o intérprete, uma concepção pragmática.

Validade é a qualidade da norma que exprime uma relação hierárquica das normas entre si; uma norma válida signilica, portanto, que ela guarda uma relação com outra norma, relaçăo esta de natureza hierárquica.

HANS KELSEN\& vê a validade da norma como um problema sintático de relação da relaçăo entre nomas.

RUPERT SCHREIBER' laz uma classificação das normas em três tipos, dizendo que quando a doutrina usa a expressäo "validade", quer se referir a três noçöes diferentes:

a) validade constitucional; b) validade no sentido de efetividade; c) validade endereçada do usuário, numa relação entre editor e o endereçado.

A validade de natureza constitucional é de natureza hierárquica; a concepção sintática da validade é sempre de natureza constitucional, pois sempre leva ao problema da norma fundamental.

Quanto ao segundo aspecto, a validade no sentido de efetividade, é uma validade no sentido semântico; este segundo conceito também é defendido por ALF ROSS10, que explica o sentido semântico dizendo que a validade exprime, neste sentido, uma relaçäo entre a noma e a realidade; terá validade ou será válida se for adequada à realidade; não será, neste caso,

\footnotetext{
8 Apud FERRAz JUMOR, Téruio Sampalo. A cientia do direito p. 57.

${ }^{9}$ Idem, ibiciem.

10 Sobre el derecho y la justin. p. 109.
} 
a hierarquia, mas, sim, a adequação o fato gerador da validade.Segundo ROSS, esta adequação pode ser medida. Desde que a norma seja aplicada pelos tribunais, desde que esteja atuando, diz ROSS, estão usando as normas com a consciência de que devem ser usadas. ROSS se opōe, portanto, a KELSEN.

Sob o ponto de vista da pragmática, a validade da norma representa uma relação de imunização. A norma é uma relação de imunização do editor, em face do endereçado. A autoridade do editor fica vacinada contra eventuais críticas do endereçado; havendo esta imunização, diz-se que a norma é válida.

\subsection{O Problema da Efetividade}

A noção de efetividade da norma jurídica é ungida à correspondência entre aquilo que a norma prescreve e o comportamento humano diante do prescrito.

Se, no triângulo semiótico, substituir-se o signo pela norma, estabelecer-se-ão três relações:

a) norma à norma - relação sintática; b) norma ao objeto - relação semântica; c) norma ao usuário - relação pragmática. Na relação norma - objeto, na relação semântica, ter-se-á a efetividade semântica.

Na relação norma - norma, na relação sintática, ter-se-á a efetividade sintática, que corresponde à possibilidade de produzir efeitos, também chamada de eficácia. Esta efetividade sintática apresenta dois casos: a possibilidade cle produção imediata de efeitos e a possibilidade de produção mediata de efeitos.

No segundo caso - possibilidade mediata de produção de efeitos, dizse que há elicácia, que é dividida em duas: eficácia contida e eficácia limitada.

Ocorre a eficácia contida quando a norma precisa de uma outra norma para produzir eleitos; por exemplo: a lei que, para produzir efeitos, precisa de ser regulamentada, possui eficácia contida, porquanto, enquanto não houver a regulamentação, há contenção da eficácia. 
Ocorre a eficácia limitada quando a norma precisa de outra produção nomativa, como no caso das normas pragmáticas, que constam do texto constitucional. Exemplo: a Constituição determina a destinação de recursos públicos às escolas públicas e comunitárias, na forma determinada por leis especiais; estas leis especiais vêm a se constituir um novo elenco de produção normativa, para que surjam os efeitos pretendidos pela norma anterior ${ }^{11}$.

Sob o ponto de vista pragmático, são estudadas estas duas formas de noção da efetividade: tanto na relação semântica, quanto na relação sintática.

Sabe-se que do ponto de vista da pragmática, as normas têm, sempre, um cometimento e um relato. O cometimento estabelece uma relação autoridade $\mathrm{x}$ sujeito; isto é, o emissor das normas estabelece uma autoridade e o endereçado da norma é estabelecido como sujeito. Pelo relato, prescrevese alguma coisa.

Sabe-se que, quem fala não transmite apenas uma informaçäo (relato), mas, transmite ao mesmo tempo como esta informação deve ser entendida (cometimento); isto é, quem fala - o orador ou emissor, informa e determina a relaçăo entre si próprio e o seu ouvinte - o endereçado.

Pois bem, a noção de efetividade nada mais é que a relação de adequação do relato ao cometimento.

Haverá norma efetiva se houver adequação do relato ao cometimento; exemplo: nesta sala, é proibido fumar.

Năo haverá efetividade se não houver esta adequação; exemplo: nesta sala é proibido subir nas árvores; o relato - subir nas árvores, é totalmente inadequado ao cometimento, não chegando a estabelecer a relação autoridade $\mathrm{x}$ sujeito.

Quando ocorre esta adequação, diz-se que a norma é efetiva porque a comunicaçäo normativa é bem sucedida - tem sucesso!

O sucesso da comunicação nomativa gera a efetividade da norma.

11 G art 213 da Comstumicto Federat. 


\section{O DISCURSO NORMATIVO}

Discurso, na linguagem universitária, é "um conjunto de fatos lingǘrsticos ligados entre si por regras sintáticas de construção"12.

$O$ discurso normativo, aquele que encerra a comunicação da norma, tem múltiplas definiçóes, tendo RUEDIGER LAUTMANN13 catalogado 82 variaçes.

A doutrina jurídica tradicional tem preferido indicar o caráter imperativo dos enunciados, para embasamento da definição do discurso normativo.

Incontestavelmente, o discurso normativo funda-se no princípio da interação, através da qual o comunicador transmite aos destinatários a mensagem notmativa; com uma vantagem: há, no discurso normativo, uma inversa do "ônus probandi" que, no discurso-contra, heterológico, de estrutura dialógica, cabe ao emissor, enquanto que naquele, cabe ao receptor o onus de provar as razöes de sua recusa à informaçăo normativa. Esta é uma das mais importantes características do discurso normativo: destinando-se a açáo lingüistica do comunicador a dirimir um conflito entre as partes, sua decisão é válida, independentemente das expectativas e reaçōes dos endereçados.

Ha, no discurso normativo, trés regras especficas:

a) a primeira regra da imputação do dever de prova pela recusa da comunicação ao endereçado; b) a segunda regra: da garantia do conflito; ) a terceira regra: da exigibilidade, que confere ao comunicador normativo o seu carater contrafático.

O discurso normativo é dialógico e monológico e, em consequência, seu objelo é um "certum" e um "dubium" a um só tempo.

É objeto "certum" na relação autoridade/sujeito (de estrutura monológica) e é objeto "dubium" tendo em vista a relação parte argumentante/intérprete, de estrutura dialógica.

\footnotetext{
12 FOUCAULT, Michel Apul FERAZ jUNYOR, Tercio Sampaio. Teora da noma juridica p. 08.

13 Apul FERRAZ JUNTOR Terclo Sampalo. Teoria da norma juridica. p. 36
} 
Neste segundo aspecto, compreende-se porque todas as açóes lingüísticas do comunicador normativo podem ser postas em dúvida pelo ouvinte, resultando a necessidade de diálogos parciais, para a obtenção de enunciados primários persuasivos, a partir dos quais o diálogo se instala.

Normas jurídicas são regras; săo decisōes. Consequentemente : o discurso normativo é um repositório de decisỏes e de regras, através das quais são estabelecidos controles, cuja finalidade é de determinar outras decisões.

Pode-se, pois, afirmar, que o objeto do discurso normativo é a comunicação de regras e de decisões, inclusive nos casos onde possa haver uma alternativa de decisoes.

No discurso normativo, o relato e o cometimento formam, no seu conjunto, o objeto ("quaestio") a ser decidido.

\section{O PROBLEMA DA SANÇAOO}

$A$ questão da relação entre o discurso normativo e a sanção, sob o ponto de vista pragmático, decorre da própria ambiguidade do discurso, que é diálogo e monólogo, concomitantemente. Ao nivel do cometimento ele é, basicamente monólogo, enquanto que o nivel do relato ele é diálogo. Toda lei se impóe e näo se pode discutir o carăter positivo da lei; entretanto, concomitantemente, embora não se possa recusá-la, pode-se discuti-la e interpretá-la.

Resultam, daí, dois caracteres: dogmaticidade e interpretabilidade, em razão dos quais é licito se perguntar: o caráter de coercitividade do discurso normativo está ou não ligado à sanção?

Tal indagação é perfeitamente justificada face à existência de normas independentes que prevêem a sanção e normas dependentes que têm a sanção em outra norma.

HANS KELSEN14 reconhece que a sanção é elemento essencial da norma e que há normas independentes e dependentes, sendo estas ligadas à

14 Toria pura do dieclo 0.52 
uma última e hipotética norma não sancionadora e que é o fundamento e alicerce de toda a ordem juridica.

A temática da sanção enseja triplice aspecto:

a) o que é sanção? Qual é seu sentido? b) qualé a relação entre norma e sanção? Toda norma tem de prever uma sançăo ou pode haver norma desprovida de sancionabilidade? c) qual é fundamento da norma na sanção? É o direito uma forma de violência?

Quanto ao primeiro aspecto, pode-se dizer que sanção é a consequência do ilicito ou delito, prevista no próprio ordenamento juridico, dentro daquele aforisma representativo do positivo jurídico: "nullum crimen sine previa lege"; mesmo que determinado fato seja indesejável ou nocivo, ele não será ilícito se não se constituir em pressuposto da aplicação de um ato coercitivo.

Quanto ao segundo problema (relação entre norma e sanção), deve-se examinar se toda norma, mesmo que näo preveja uma sanção, se se constitui numa ameaça de sanç̃o; sabe-se que há normas que prescrevem condutas e estabelecem a meta complemetariedade autoridade/sujeito, destituidas de ameaças de sanção; esta, porém, é encontrada em outra norma e, por conexão é aplicada.

Finalmente, quanto ao terceiro aspecto, parece não haver dúvida que uma das características da noma jurídica estar inserida nela a previsibilidade da sanção; a sanção não deve ser considerada, contudo, como a causa genética do Direito. Não é por outra razão que RODOLF VON IHERTNG, deline Direito como sendo "o conjunto de normas coativas validas num Estado (...)"15, acrescentando que esta definição é que mais lhe agrada porque atingiu perfeitamente o essencial, os dois fatores básicos: norma e coaçào.

\section{SITUAÇÖES JURIDICAS SUBJETIVAS}

Depois do estudo feito sobre os três aspectos do problema da sanção dentro da noma - o que é sanção?, qual é o papel da sanção dentro da 
norma? a sanção constitui ou não fundamento da norma?, chega-se à identilicaça dos elementos necessários para a caracterização das chamadas situaçoes juridicas subjetivas.

Estes elementos são três:

a) noça de norma, como relação meta-complementar entre as partes; b) a noção de sancáo, como elemento do aspecto-relato da norma; c) noça do editor normativo como autoridade e de enderecado como sujeito.

Quanto à noção de norma, como relaçăo meta-complementar, viu-se que o comunicador normativo se coloca perante os endereçados numa posição hierarquicamente dilerente; inicialmente, numa relação complementar, de natureza indosincrática; esta complementariedade imposta, estabelecida, recebe a denominação de relação meta-complementar.

Quanto à noção de sanção, viu-se que, sob o ponto de vista normativo e discursivo, a sanção é um fato lingüistico constitutivo de uma ameaça ou de um castigo socialmente desagradável.

Sanção, como diz HANS KELSEN1ó, não é uma palavra de fácil definição, porquanto tem ela váras significações; inclusive, o verbo sancionar pode significar o "referendum" aposto pelo Presidente da República a lei elaborada pelo Poder Legislativo. Mas, de uma maneira geral, a noção de sançāo está ligada à idéia de um castigo, como um mal socialmente reconhecido.

Finalmente, quanto à noção do editor normativo, vimos quais são os papéis que as pessoas assumem na relação meta-complementar; a diferença entre normas de obrigação e normas permissivas. Identificados esse elementos, constata-se que o discurso normativo é um discurso-contra, de estrutura ambigua, com aspectos dialogicos e monológicos, com controle das reaçoes do ouvinte discursivo, pelo orador, com inversão do ônus de prova.

Podem ser distinguidas três situações subjetivas juridicas básicas: a) obrigação ou dever juridico; b) poder juridico; c) direito subjetivo.

As situaçōes subjetivas juridicas indicam posições variáveis do sujeito, dentro do discurso normativo, que é interação, posições estas que se 
modificam de conlormidade com as forças argumentativas do seu discurso.

Sujeito da obrigação não é apenas aquele que pode evitar a sançāo, mas também aquele que se encontra em relação meta-complementar perante o editor normativo.

\subsection{O Poder Juridico}

Para existir o poder jurídico, há necessidade de uma norma permissiva, cujo relato autoriza a ediçáo de nomas e de uma norma de obrigação, cujo relato autoriza a aplicação de sanção aos contraventores da norma permissiva.

A conexăo destas duas normas gera o poder jurídico, que representa a possibilidade de ser editada norma para restabelecer a relação autoridade $\mathrm{x}$ sujeito.

O poder juridico é o criador da normas de competencia, conhecidas por denominaçoes diversas: normas secundárias, normas de $2^{\circ}$. grau e, ainda, normas de organização.

As normas de competência têm por caracteres primordiais: são permissivas e são normas de conhecimento, porquanto autorizam editar normas e reconhecem a validade de outras normas.

Quando se diz, por exemplo, "o Chefe do Departamento está autorizado a resolver os casos, dentro de sua competencia funcional", se quer dizer que o Chefe do Departamento está autorizado a editar normas, para decidir os casos submetidos à sua apreciaçăo, normas estas que săo reconhecidas, prioristicamente, como válidas.

Estas normas que compöem o poder jurídico têm as funçöes de reconhecer, ligar, julgar e de organizar; diz MIGUEL REALE ${ }^{17}$ que elas organizam outras normas.

As normas permissivas, além de reconhecer a validade de outras normas, também provocam a mudança de outras normas.

17 Fitoofin do tireto. p. 565 . 
Na noção de poder juridico está inserida a questão do comportamento que contraria a noma, comportamento este sujeito às nomas de obrigação que sancionam as contravençoes das normas imputadas pelo sujetio do poder.

A violação da norma permissiva se dá ao nivel do cometimento e näo ao nivel do relato. Neste sentido, a norma permissiva acaba provocando uma consequência, que não é, propriamente, a da aplicaçăo da sanção, porquanto esta está sempre no nivel do relato, ou seja, da conduta prescritiva.

Portanto, quando o cometimento é violado, a única coisa que acontece, que não é sanção, só pode ser a nulidade. Por esta razão, pode-se alimar que o problema das nulidades está ligado ao cometimento e não ao relato.

\subsection{Direito Subjetivo}

Existem certas palavras que têm função designativa; basta ouvi-las e jả vêm à mente os objetos que elas designam; por exemplo: mesa, cadeira, livro.

Há outras palavras, porém, que não têm definição ostensiva; são palavras ocas, vazias, que näo traduzem os objetos a que se referem. Menciona-se, como exemplo de uma expressão oca, a expressão "libra esterina"; quem a ouve, näo pode criar a imagem do objeto que the corresponde. Transportando para o direito estes mesmos conceitos, verificase que há palavras, no mundo jurídico, que também não têm função designativa. Uma delas é "direito subjetivo", como também o é "propriedade".

Assim, quando se fala de propriedade, a que se está referindo? Ao direito do proprietario? Ao objeto possuido? A um direito real?

Ainda, no caso da propriedade, onde está o direito subjetivo? Na escritura pública? No registro do titulo no cartório de imóveis?

Resulta, portanto, a necessidade de ser delinido o que signilica "direito subjetivo".

Algumas palavras ocas do Direito têm função social e a funçăo mágica ou mística. 
Assim, por exemplo, "jus" é uma palavra mágica ou mistica, porquanto cria certos efeitos. Direilo subjetivo é também una expressão mágica ou mística, porquanto estabelece uma vinculação entre dois sujeitos e facilita a comunicação humana.Direito subjetivo de propriedade, por exemplo, significa que, sobre determinada pessoa incidem normas que, por sua vez, tên ligação com uma série de outras pessoas.

A expressão direito subjetivo de propriedade facilita $\circ$ entendimento respeitantemente à transferência da propriedade.

Por outro lado, a expressão "direito subjetivo" tem uma função técnica, tem operacionalidade limitada, restrita. Direito subjetivo é um problema de conexão de normas permissivas e normas de obrigação.

Quando surge o direito subjetivo como objeto da reflexão?

Os juristas romanos, que se não distinguiram no direito público (no qual se destacaram os gregos) não tiveram a noção de Estado, mas criaram os conceitos de "norma agendi" e de "facultas agendi".

Na expressão direito subjetivo há uma norma permissiva simétrica. Por exemplo: "É permitido fumar". O editor se coloca numa posiçäo igual ao endereçado; o editor é igual ao receptor. Para que surja o direito subjetivo há necessidade da auto imposição. A auto limitação cria um problema para a autoridade no sentido de isentar o ônus da prova.

Como explicar esta situação? É através da referência à divisão dos poderes. A obrigação de um poder dado a outro poder. Dai surgiu o Estado, como organização burocrática. A divisão dos poderes é um princípio ordenado que assegura um equilibrio de forças, tornando possivel a realização dos compromissos.

Este equilíbrio não permite a predominância de uma sobre a outra. $O$ Direito subjetivo resulta de um equilíbrio de forças.

\section{REFERENCIAS BIBLIOGRÁFICAS}

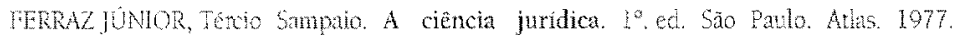

Teoria da norma juridica. $1^{\circ}$ ed, Rio de Janciro. Forense. 1978.

KELEEN, lims. Teoria pura do direito. $4^{*}$ ed. Coimbra. Armento Amado 1976.

REAT, Miguel. Filosotia do direito. $17^{\circ}$ cd. São Pauio. Saraiva 1900.

ROS5, All. Sobre el derecho y la justitia. [s.ed.] Buenos Aires. Eudeba.1963. 